\title{
Dental Cyst Occupying the Branch Region and Mandibular Body with Displacement from the Third Molar to the Condition Region
}

\author{
Caio Peres Bellato ${ }^{1}$, Thiago Calcagnotto ${ }^{2}$, Camila de Souza Arantes ${ }^{3}$, Eduardo Sanches Gonçales ${ }^{1}$, \\ Victor Tieghi Neto', Danilo Louzada de Oliveira ${ }^{4}$ \\ ${ }^{1}$ Department of Surgery, Pathology, Radiology and Stomatology, Bauru School of Dentistry, University of Sao Paulo, Bauru, Brazil \\ ${ }^{2}$ Coordinator of the Specialization Course in CTBMF at Faculdade Tecnológica Dental CEEO, Brazil \\ ${ }^{3}$ Department of Endodontics, University Paulista State, Araçatuba, Brazil \\ ${ }^{4}$ Department of Surgery, University of West Paulista, Presidente Prudente, Brazil \\ Email: caiobellato@usp.br
}

How to cite this paper: Bellato, C.P., Calcagnotto, T., de Souza Arantes, C., Gonçales, E.S., Neto, V.T. and de Oliveira, D.L. (2020) Dental Cyst Occupying the Branch Region and Mandibular Body with Displacement from the Third Molar to the Condition Region. Open Access Library Journal, 7: e6875.

https://doi.org/10.4236/oalib.1106875

Received: October 11, 2020

Accepted: November 9, 2020

Published: November 12, 2020

Copyright (c) 2020 by author(s) and Open Access Library Inc.

This work is licensed under the Creative Commons Attribution International License (CC BY 4.0).

http://creativecommons.org/licenses/by/4.0/

\begin{abstract}
The dentigerous cyst is the second most frequent odontogenic cyst after the root, being typically asymptomatic and commonly incidentally diagnosed. The objective of this case was to describe a successful treatment of a dentigerous cyst associated with an unerupted lower third molar, which extended from the condyle to the premolar region, treated by decompression followed by surgical enucleation. That said, a 19-year-old female patient, black, without underlying pathologies, came to the dental office for extraction of the third molars, and after a preoperative orthopantomographic radiography, the displacement of the dental element was noted 38 for the condylar region, unilocular cystic lesion occupying the branch and mandibular body region, root resorption of the dental elements involved in the region and rejection of the mandibular canal. After cytopathological analysis of the material collected through fine needle aspiration, the diagnosis of infected dentigerous cyst was confirmed. Afterwards, extraction and decompression were performed followed by surgical enucleation. Thus, it is concluded that the treatment performed promoted a satisfactory result, given a spontaneous bone neoformation after decompression and surgical enucleation of the lesion.
\end{abstract}

\section{Subject Areas}

Dentistry

\section{Keywords}

Dentigerous Cyst, Molar Third, Bone Cysts 


\section{Introduction}

The dentigerous cyst is a cyst of odontogenic origin, associated with the crown of an unerupted permanent tooth, most often the lower third molars and upper canines. It is the second most frequent maxillary cyst (14\% - 20\%), after periapical root cysts [1].

This pathological condition is usually found in radiographic examinations performed for another purpose, especially when investigating the non-eruption of a permanent tooth. They are always radiolucent, commonly unilocular, with greater occurrence in the mandible and in males, however, large lesions may present a multilocular pattern [2].

Clinically, these lesions are, most of the times, of slow and asymptomatic growth, which occurs mainly in the first three decades of life, however, they can grow considerably and cause expansion of the bone cortex, this is due to the accumulation of fluid between the epithelium reduced enamel and enamel surface [3].

The present study shows a successful treatment of a dentigerous cyst associated with an unerupted lower third molar, which stretched from the condylar region to the premolar region, treated by decompression followed by surgical enucleation.

\section{Case Report}

A 19-year-old female patient, black, with no underlying pathologies, came to the dental office for extraction of asymptomatic third molars. In the intraoral examination, no abnormal condition was observed, and a complementary image exam was requested for exodontic planning.

After acquisition and analysis of the preoperative orthopantomographic radiography, it was noted the displacement of dental element 38 to the condylar region, unilocular cystic lesion occupying the region of the mandibular branch and body, root resorption of the dental elements involved in the region and rejection of the mandibular canal to the mandibular basal bone (Figure 1).

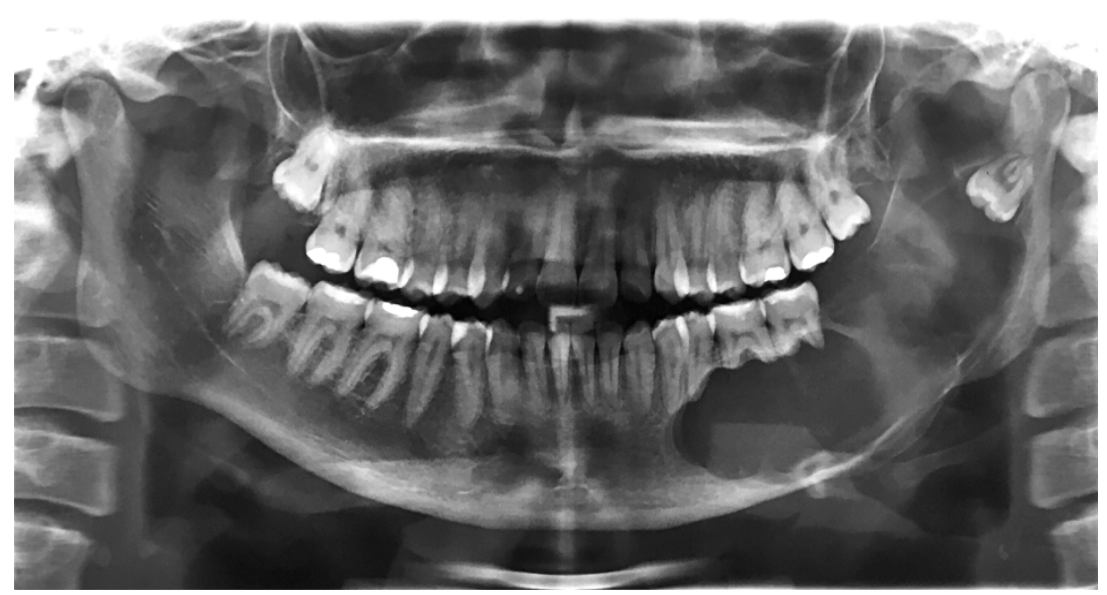

Figure 1. Preoperative panoramic radiography. 
The importance of the biopsy was discussed with the patient, giving her approval. For this, intrabucal antisepsis was performed with $0.12 \%$ chlorhexidine digluconate mouthwash (PerioGard; Colgate-Palmolive, Salford, United Kingdom) for one minute and after local analgesia was achieved by regional oral and lower alveolar nerve block with $2 \%$ articaine with 1:100,000 adhaline (3M ESPE, Seefeld, Germany), the collection of the intra-cystic fluid was performed through fine needle aspiration, confirming the diagnosis of infected dentigerous cyst.

After obtaining the diagnosis and taking into account the extent of the lesion, the extraction of the dental element 38 and surgical decompression through a Penrose type drain were performed at first, in order to decrease the extent of the cystic lesion. This suture to the edge of the surgical wound allows the creation of a "secondary compartment" with the oral cavity, ensuring that the cystic cavity remains open and a drainage path is formed [4].

After radiographic control was performed after 60 days, it was possible to visualize the decrease in the extent of the lesion, suggesting a local bone neoformation, this due to the radiographic radiopacity, so we opted for the surgical enucleation of the lesion, with subsequent referral of the patient for endodontic treatment of the dental elements. involved in the injury (Figure 2).

The radiographic control of 90 days, after enucleation, extraction and endodontic treatment of the teeth involved in the lesion, a new bone formation was observed in the entire extension of the cystic lesion (Figure 3 ).

\section{Discussion}

Dentigerous cysts are benign, associated with the crowns of unerupted teeth. Its occurrence generally occurs in the 3 rd and 4 th decade of life [3]. In contrast to this finding, the patient in our study was 19 years old; this age difference can be attributed to the ethnicity difference of the examined population.

The most common site of involvement is the third mandibular molars followed by the maxillary canines [5], thus corroborating the region affected in our study, this may be due to the fact that these two groups of teeth are the most

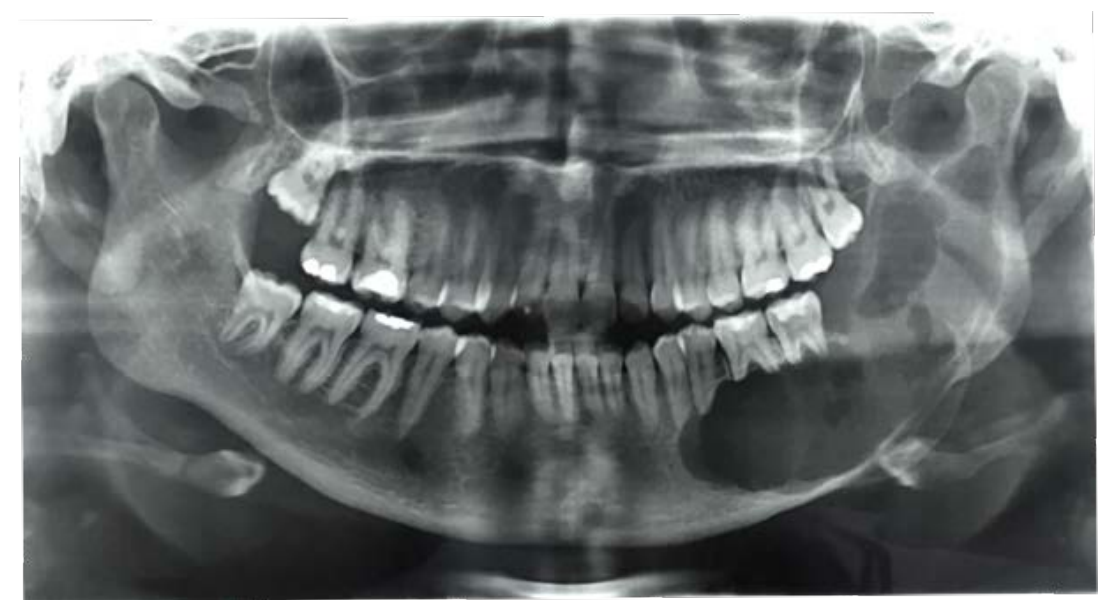

Figure 2. Radiographic control after decompression and extraction. 


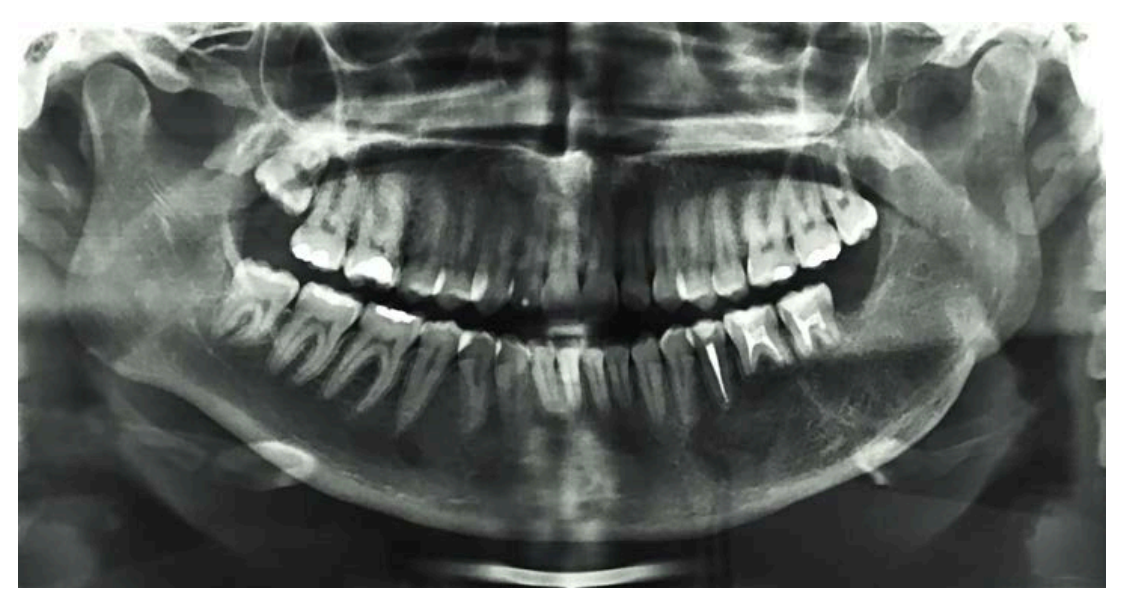

Figure 3. New bone formation in the entire length of the cystic lesion.

commonly affected by impaction [6].

According to Benn and Altini [7], there are three viable mechanisms for the histogenesis of the dentigerous cyst, which can be formed from dental follicle, as in the case presented here, from a root cyst, which is formed at the apex of a deciduous tooth non-vital and from a periapical inflammation of a deciduous non-vital tooth or other source, which spreads to surround the follicle of the permanent successor.

The surgical approach for cystic jaw injuries is decompression, marsupialization and/or enucleation. The treatment of choice depends on the size and location of the lesion, the bone integrity of the cystic wall and the proximity of vital structures [8].

Sometimes, after marsupialization or decompression, the eruption of the associated impacted teeth takes on an unusual position and when it is not possible to be pulled orthodontically, it must be extracted [9]. In the case presented, the decompression was performed before enucleation, as it is a cystic lesion very extensive and may cause a mandibular fracture if it were removed completely, without decompression beforehand. The extraction of tooth 38 was also performed, since it is not possible to place this dental element in the alveolar arch.

\section{Conclusion}

The present article showed that the treatment performed promoted a satisfactory result, given the spontaneous bone neoformation after decompression and surgical enucleation of the lesion with removal of the lower third molar. It is important to emphasize that the choice of treatment must consider conservative management with low morbidity, especially in young patients.

\section{Conflicts of Interest}

The authors declare no conflicts of interest regarding the publication of this paper. 


\section{Consent}

The patient had given his consent for this case report to be published. This Statement is in the cover of the chart.

\section{References}

[1] Scolozzi, P., Lombardi, T. and Richter, M. (2005) Upper Lip Swelling Caused by a Large Dentigerous Cyst. European Archives of Oto-Rhino-Laryngology, 262, 246-249. https://doi.org/10.1007/s00405-004-0782-4

[2] Ikeshima, A. and Tamura, Y. (2002) Differential Diagnosis between Dentigerous Cyst and Benign Tumor with an Embedded Tooth. Journal of Oral Science, 44, 13-17. https://doi.org/10.2334/josnusd.44.13

[3] Shear, M. (2007) Speight Paul Cysts of the Oral and Maxillofacial Regions. 4th Edition, Blackwell Publishing, Bristol. https://doi.org/10.1002/9780470759769

[4] Partsch, K. (1892) Ueber Kiefercysten. Deutsche Monatschrift für Zahnheilkunde.

[5] Manickam, S., Mandana, D. and Praveen, S.B. (2012) Analysis of 153 Cases of Odontogenic Cysts in a South Indian Sample Population: A Retrospective Study over a Decade. Brazilian Oral Research, 26, 330-334. https://doi.org/10.1590/S1806-83242012005000007

[6] Lin, H.P., Wang, Y.P., Chen, H.M., Cheng, S.J., Sun, A. And Chiang, C.P. (2013) A Clinicopathologic Study of 338 Dentigerous Cysts. Journal of Oral Pathology \& Medicine, 42, 462-467. https://doi.org/10.1111/jop.12042

[7] Benn, A. and Altini, M. (1996) Dentigerous Cysts of Inflammatory Origin. A Clinicopathologic Study. Oral Surgery, Oral Medicine, Oral Pathology and Oral Radiology, 81, 203-209. https://doi.org/10.1016/S1079-2104(96)80416-1

[8] Scott, B. (1997) Otolaryngology. Vol. 5, 6th Edition, Butterworth-Heinemann, UK, 5-6.

[9] Hyomoto, M., Kawakami, M., Inoue, M. and Kirita, T. (2003) Clinical Conditions for Eruption of Maxillary Canines and Mandibular Premolars Associated with Dentigerous Cysts. American Journal of Orthodontics and Dentofacial Orthopedics, 124, 515-520. https://doi.org/10.1016/j.ajodo.2003.04.001 